\title{
DISTRIBUIÇÃO DE POTÁSSIO E DE RAÍZES NO SOLO E CRESCIMENTO DE MILHO EM SISTEMAS DE MANEJO DO SOLO E DA ADUBAÇÃO EM LONGO PRAZO(1)
}

\author{
Sérgio Ely Valadão Gigante de Andrade Costa ${ }^{(2)}$, Edicarlos Damacena \\ de Souza ${ }^{(3)}$, Ibanor Anghinoni ${ }^{(4)}$, João Paulo Cassol Flores ${ }^{(5)} \&$ \\ Marcelo Hoerbe Andriguetti ${ }^{(6)}$
}

\begin{abstract}
RESUMO
O manejo do solo e da adubação potássica pode influenciar a distribuição de $\mathrm{K}$ e de raízes no solo, a absorção desse nutriente e o crescimento do milho. Com o objetivo de entender melhor essas inter-relações, foi realizado um experimento em um Argissolo Vermelho distrófico, há 18 anos, sob diferentes sistemas de manejo. Amostragens detalhadas do perfil do solo foram efetuadas no início da fase de enchimento de grãos de milho na safra 2006/07, nos seguintes tratamentos: preparo convencional (Con), com adubação potássica em linha (Lin), a lanço (Lan) e em faixa (Fx); sem preparo (Dir), com adubação em linha (Lin) e a lanço (Lan); e preparo em faixa $(F x)$, com adubação em faixa $\left(F_{x}\right)$. Independente do manejo do solo e da adubação, o K formou gradientes a partir da superfície do solo e em torno do colmo do milho. Os gradientes, no entanto, foram diferenciados em relação ao manejo do solo, concentrando-se mais na superfície em plantio direto, independente do modo de adubação. As raízes de milho se concentraram na camada superficial do solo, com maior crescimento em plantio direto. A absorção de $\mathrm{K}$ e o crescimento do milho não foram associados à distribuição desse nutriente e de raízes no solo. A eficiência de utilização de $K$ pelas plantas foi favorecida pela aplicação do adubo potássico a lanço, independente do preparo do solo.
\end{abstract}

Termos de indexação: preparo do solo; adubação potássica, eficiência de uso.

\footnotetext{
(1) Parte da Dissertação de Mestrado do primeiro autor aprsentada junto ao Programa de Pós-Graduação em Ciência do Solo, Universidade Federal do Rio Grande do Sul - UFRGS. Recebido para publicação em julho de 2008 e aprovado em julho de 2009.

(2) Mestrando em Ciência do Solo, Universidade Federal do Rio Grande do Sul - UFRGS. Av. Bento Gonçalves 7712, CEP 91540000 Porto Alegre (RS). Bolsista CAPES. E-mail: sergioelycosta@hotmail.com

(3) Bolsista Prodoc. Universidade Federal de Goiás-Jataí. Caixa Postal 03, CEP 75804-020 Jataí (GO). Bolsista Prodoc CNPq. Email: edidamacena2000@yahoo.com.br

(4) Professor Colaborador, Departamento de Solos, UFRGS. Bolsista CNPq. E-mail: ibanghi@ufrgs.br

${ }^{(5)}$ Doutor em Ciência do Solo, UFRGS. E-mail: joaopcflores@yahoo.com.br

${ }^{(6)}$ Acadêmico do curso de Agronomia, UFRGS. Bolsita CNPq.
} 


\title{
SUMMARY: POTASSIUMAND ROOT DISTRIBUTION IN SOIL AND CORN GROWTH IN LONG-TERM SOIL MANAGEMENT AND FERTILIZATION SYSTEMS
}

\begin{abstract}
Soil tillage systems can greatly influence potassium and root distribution in the soil and, as a result, affect corn growth and development. To improve the understanding of these interrelationships, a soil was analyzed after 18 years of cultivation under different management systems. A detailed soil sampling was carried out in a clayey Red Argisol (Udult) profile in the beginning of the grain filling stage of corn in the 2006/07 growing season. The experimental design consisted of a completely randomized scheme with two replicates, with the following treatments: conventional tillage (Con) and no-tillage (Dir) with potassium fertilization: along the rows (Fx), broadcast (Lan) and in stripes (Lin). Independently of the soil and fertilizer management, potassium formed gradients from the soil surface downwards and around the corn plant stem. The gradients, however, differed according to the soil management; concentrations were higher at the surface under no-tillage, regardless of the fertilization method. Maize roots were concentrated predominantly in the soil surface layer, with greater growth in no-tillage. Potassium uptake and maize growth were not associated with K distribution in soil and roots. The efficiency of $K$ use by plants was increased by the broadcast application of potassium fertilizer, regardless of the tillage system.
\end{abstract}

Index terms: soil tillage, potassium fertilization, use efficiency

\section{INTRODUÇÃO}

A distribuição de nutrientes no solo é influenciada por diversos fatores, entre os quais destacam-se o preparo solo e o modo de aplicação de fertilizantes. A umidade do solo é outro fator a ser considerado na avaliação do suprimento de nutrientes às raízes, especialmente naqueles em que este processo ocorre predominantemente por difusão, como o K (Barber, 1995). A disponibilidade de água no solo, por sua vez, é influenciada pelo manejo do solo, afetando o crescimento e desenvolvimento das plantas.

As plantas, em geral, têm uma demanda inicial de K elevada, acumulando cerca de $40 \%$ de todo o K necessário para seu desenvolvimento em apenas 52 dias após a emergência (Karlen et al., 1988). Além disso, pelo fato deste nutriente não ser componente estrutural da planta, ele tem elevado potencial de ciclagem em sistemas com adição contínua de resíduos (Rossato, 2004). Um período em torno de 52 dias pode ser suficiente para que aproximadamente $90 \%$ do K contido no resíduo vegetal seja liberado (Lupwayi et al., 2005). A dinâmica do K pode ser afetada também pelo aumento dos teores de carbono orgânico (CO) (Bayer \& Mielniczuk, 1997), que, a longo prazo, causa um incremento na capacidade de troca de cátions (CTC) do solo, podendo alterar as doses e o manejo da fertilização potássica (Kayser \& Isselstein, 2005).

Aspectos relacionados com a adoção de formas de aplicação de fertilizantes e sistemas de manejo do solo e o consequente efeito na dinâmica de nutrientes e crescimento de plantas têm sido pouco estudados no Brasil (Model \& Anghinoni, 1991; Klepker \& Anghinoni, 1995). O modo de aplicação de fertilizantes potássicos merece especial atenção devido à suscetibilidade do K a perdas por processos erosivos, principalmente em solos com baixa CTC (Mielniczuk, 2005), e também ao elevado grau de salinidade do cloreto de $\mathrm{K}(\mathrm{KCl})$, principal fonte de $\mathrm{K}$ utilizada na agricultura (Bevilaqua et al., 1996). Os cuidados ao utilizar o $\mathrm{KCl}$ como fonte de $\mathrm{K}$ se justificam, pois aplicações a lanço podem não fornecer a quantidade de nutriente necessária ao desenvolvimento inicial das plantas (Heckman \& Kamprath, 1992), ao passo que aplicações na linha, em doses elevadas, podem resultar em danos ao sistema radicular (Salton et al., 2002).

Em áreas sob sistema de plantio direto (SPD) consolidado, tem sido verificado um acúmulo de $\mathrm{K}$ na camada superficial do solo (0-5 cm) (Ketcheson, 1980; Eltz et al., 1989). Esse acúmulo, aliado à maior disponibilidade hídrica nesse sistema de manejo, pode resultar em maior disponibilidade de K em relação ao sistema convencional de cultivo (SCC) (Bordoli \& Mallarino, 1998). O revolvimento periódico do solo e a deposição de fertilizantes potássicos em camadas mais profundas parecem ser alternativas viáveis para aumentar os teores de K em profundidade, aliviando o efeito da estiagem sobre o suprimento de K para as plantas (Rehm, 1995). A distribuição do K no perfil parece ser independente do grau de revolvimento do solo e, ou, do modo de aplicação de K (Model \& Anghinoni, 1991).

O sistema de manejo do solo pode afetar também a distribuição de raízes no solo (Mello Ivo \& Mielniczuk, 1999; Motta et al., 2006). A longo prazo, essas alterações ocorrem em diferentes profundidades (Ishaq et al., 2003). O revolvimento do solo influencia positivamente a taxa de crescimento radicular inicial 
e o desempenho da cultura (Petersen, 2008). Dessa forma, a mobilização intermediária do solo, como ocorre nos preparos em faixa a longo prazo, proporciona melhor movimento e armazenamento de água no perfil do solo, criando condições adequadas para o desenvolvimento inicial da cultura e aprofundamento do sistema radicular. O acúmulo de matéria orgânica e de nutrientes na superfície do solo em áreas sob SPD pode resultar na restrição do crescimento radicular em profundidade (Ball-Coelho et al., 1998). A distribuição do K no solo está, então, relacionada à distribuição do sistema radicular (Klepker \& Anghinoni, 1995), inclusive influenciando a morfologia das raízes (Rosolem et al., 2003).

Este estudo teve por objetivo avaliar o efeito de modos de preparo do solo e de aplicação de adubo potássico por longo tempo, na distribuição de K e de raízes no solo e sua relação com a absorção, o crescimento e a eficiência de utilização de $\mathrm{K}$ pelo milho.

\section{MATERIAL E MÉTODOS}

Este ensaio foi conduzido num experimento instalado em 1988 em um Argissolo Vermelho distrófico típico (Embrapa, 2006), com textura franco-argilo-arenosa, localizado na Estação Experimental Agronômica da Universidade Federal do Rio Grande do Sul (EEA/ UFRGS), no município de Eldorado do Sul, região fisiográfica da Depressão Central do Rio Grande do Sul (RS). Antes da instalação do experimento, o solo apresentava elevado teor de K disponível $\left(130 \mathrm{mg} \mathrm{dm}^{-3}\right.$ - Mehlich-1). O delineamento experimental foi de blocos ao acaso, em um bifatorial 3x3, separados por uma faixa de $5 \mathrm{~m}$, em parcelas subdivididas, com três repetições, onde os métodos de preparo do solo (3) ocuparam as parcelas principais (24 x $12 \mathrm{~m})$ e os modos de adubação (3) as subparcelas (12 x 8 m).Em maio de 1988, foi feita calagem em toda área, com incorporação do calcário (uma aração + duas gradagens), visando elevar o $\mathrm{pH}$ do solo para 6,0 . Na sequência, foi cultivada aveia-preta (Avena strigosa, S.). Ao final do ciclo da aveia, foram estabelecidos os seguintes manejos do solo: preparo convencional (Con - uma aração até $15-17 \mathrm{~cm}$ de profundidade e duas gradagens); preparo em faixas ( $\mathrm{Fx}$ - faixas de $20 \mathrm{~cm}$ de largura e $15 \mathrm{~cm}$ de profundidade, centrada na linha de semeadura do milho, usando um sulcador tipo "asa de andorinha"); e sem preparo (Dir - sulco para semeadura do milho com $5 \mathrm{~cm}$ de largura e $5-8 \mathrm{~cm}$ de profundidade). Os modos de adubação potássica (K) foram a lanço (Lan), em faixa (Fx) de $20 \mathrm{~cm}(10 \mathrm{~cm}$ para cada lado do colmo) e na linha (Lin) de semeadura, sendo efetuados manualmente e após os tratamentos de preparo do solo. A sequência de culturas utilizada, a partir de outubro de 1988, foi milho (Zea mays, L.) na primavera/verão e aveia + ervilhaca (Vicia sativa) no outono/inverno. Em 1992, foi feita nova calagem nos mesmos moldes da primeira, que foi repetida a cada quatro anos a partir de então. Mais detalhes sobre a condução do experimento podem ser obtidos em Marcolan (2002).

Para este trabalho, o milho (híbrido Pioneer 30R50) foi semeado em 20/10/2006, logo após a aplicação dos tratamentos de preparo do solo e modos de adubação, com uma densidade de semeadura de 5-7 plantas $\mathrm{m}^{-1}$, com espaçamento de $1 \mathrm{~m}$ entre linhas e adubação com base em análise de solo, cujos resultados, na camada de $0-15 \mathrm{~cm}$, foram os seguintes: $\mathrm{pH}$ em água $5,2, \mathrm{P} \mathrm{e}$ $\mathrm{K}$ (Mehlich-1) 2,5 e $132 \mathrm{mg} \mathrm{dm}^{-3}$, respectivamente, e $30 \mathrm{~g} \mathrm{~kg}^{-1}$ de matéria orgânica. Para melhor caracterização do solo nos respectivos sistemas de manejo, convencional e plantio direto, foram determinados os teores de carbono orgânico total (COT) (Quadro 1) e a distribuição de agregados (Figura 1). A adubação de base constou de 60, 150 e $100 \mathrm{~kg} \mathrm{ha}^{-1}$ de $\mathrm{N}, \mathrm{P}_{2} \mathrm{O}_{5}$ e $\mathrm{K}_{2} \mathrm{O}$ na semeadura. Utilizaram-se como fontes uréia, superfosfato triplo e cloreto de $\mathrm{K}$, respectivamente, seguindo as recomendações da CQFSRS/SC (2004) para uma produtividade de grãos superior a $8,0 \mathrm{Mg} \mathrm{ha}^{-1}$. Aos 15 dias após a emergência (DAE), a população foi ajustada para 5 plantas $\mathrm{m}^{-1}$ (50.000 plantas ha-1) por desbaste manual. Nessa mesma oportunidade e aos $35 \mathrm{DAE}$, foram aplicados $60 \mathrm{~kg} \mathrm{ha}^{-1}$ de N em cobertura na forma de uréia. O cultivo do milho ocorreu em irrigação por aspersão, a qual era feita sempre que as plantas apresentavam sinais de déficit hídrico, com as folhas novas enrolando em forma de cartuchos. Em adição aos $721 \mathrm{~mm}$ de chuva no período de cultivo, foram fornecidos $150 \mathrm{~mm}$ de água de novembro a fevereiro, período de escassez hídrica (Figura 2), aplicando lâminas em torno de $25 \mathrm{~mm}$ por turno de irrigação.

Para a avaliação da distribuição de K e de raízes no solo, foram amostrados monólitos de solo no início de enchimento de grãos (8/01/07), nas seguintes combinações de modos de preparo e de adubação: Con,

\section{Quadro 1. Distribuição de carbono orgânico total no perfil de um Argissolo Vermelho submetido a sistemas de manejo: plantio direto (Dir) e preparo convencional (CON) por 18 anos}

\begin{tabular}{ccc}
\hline \multirow{2}{*}{ Camada } & \multicolumn{2}{c}{ Sistema de manejo } \\
\cline { 2 - 3 } & Dir $^{(1)}$ & Con $^{(1)}$ \\
\cline { 2 - 3 } $\mathrm{cm}$ & $19,5 \mathrm{a}$ & $\mathrm{g} \mathrm{kg}^{-1}$ \\
$0-5$ & $10,2 \mathrm{~b}$ & $11,2 \mathrm{~b}$ \\
$5-10$ & $9,0 \mathrm{~b}$ & $12,6 \mathrm{a}$ \\
$10-15$ & $9,0 \mathrm{~b}$ & $10,5 \mathrm{a}$ \\
$15-20$ & $9,1 \mathrm{a}$ & $10,4 \mathrm{a}$ \\
$20-30$ & $9,0 \mathrm{a}$ & $9,5 \mathrm{a}$ \\
$30-40$ & 11,0 & $8,6 \mathrm{a}$ \\
Média & 10,5
\end{tabular}

(1) Con: convencional; Dir: direto.médias seguidas da mesma letra na linha não diferem pelo teste de Tukey $(p<0,05)$. 


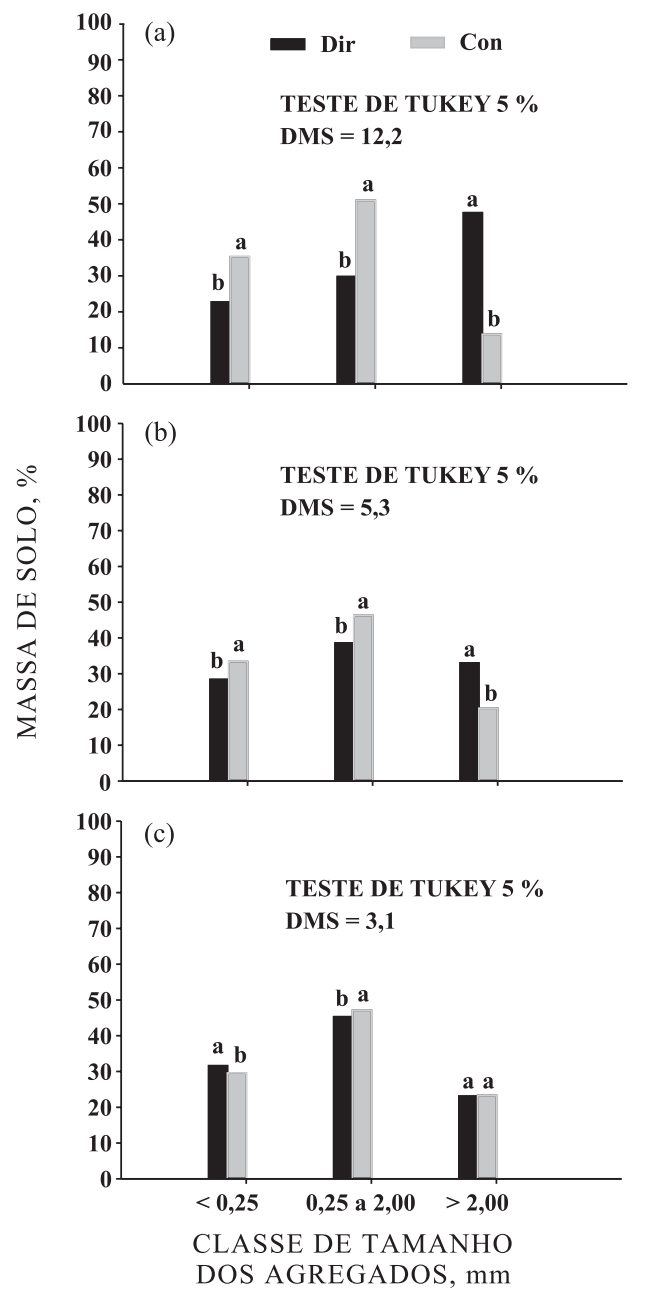

Figura 1. Distribuição das classes de tamanho de agregados em um Argissolo Vermelho no sistema plantio direto (Dir) e no preparo convencional (Con) nas profundidades de 0-5 (a), 5-10 (b) e 10-20 (c) $\mathrm{cm}$.

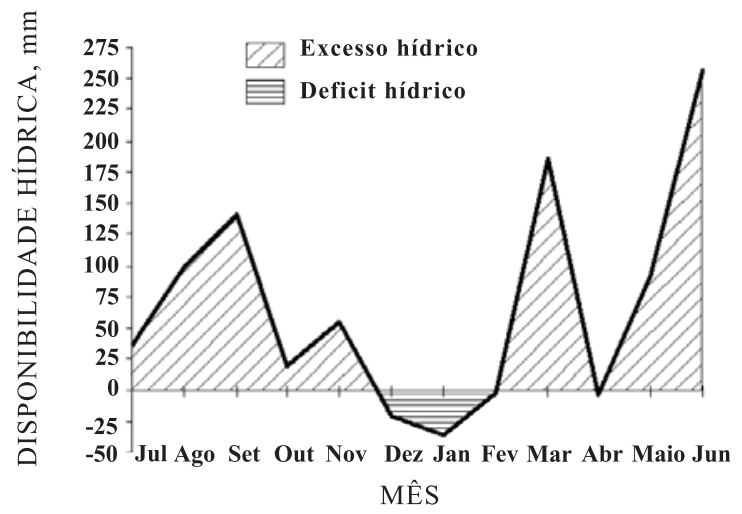

Figura 2. Balanço hídrico para capacidade de armazenamento de água na profundidade de solo (capacidade de armazenamento de $50 \mathrm{~mm}$ ) segundo Thornthwaite \& Mather (1955) no período de realização do experimento, Estação EEA/UFRGS, safra 2006/07. com revolvimento anual do solo e adubação em Fx, Lin e Lan; Dir, sem revolvimento do solo e adubação em Lin e Lan; e Fx com revolvimento do solo para incorporação do adubo em Fx. Concomitantemente à amostragem de raízes, foi coletada a planta de milho correspondente a cada monólito em duas das três repetições do experimento. Dessa forma, cada combinação entre modo de preparo e modo de adubação foi considerada um sistema de manejo do solo.

Os monólitos de solo foram coletados em pranchas de madeira com pregos metálicos, de acordo com a metodologia proposta por Schuurman \& Goedewaagen (1965), modificada por Pedó (1985). Cada monólito $(50 \times 40 \times 15 \mathrm{~cm})$ foi subdividido em quatro profundidades $(0-5,5-10,10-15,15-20 \mathrm{~cm}) \mathrm{com}$ quatro distâncias para cada lado do colmo da planta de milho (0-5, 5-10, 10-15 e 15-25 cm); e duas profundidades $(20-30$ e $30-40 \mathrm{~cm})$ com cinco estratificações horizontais (5-5, 5-15, 15-25, 25-15 e $15-5 \mathrm{~cm})$, totalizando 42 quadrículas de solo por monólito. Em cada quadrícula de solo foi efetuada a separação do solo e das raízes em camadas sobrepostas.

O comprimento radicular foi obtido por meio da utilização de imagens digitais das raízes, obtidas com auxílio de um scanner (Epson, modelo CX4100), e posterior utilização do software SIARCS 3.0 (Guimarães et al., 1997). Com os dados de comprimento radicular, foi calculada a densidade de comprimento, pela razão comprimento de raízes/volume de solo $\left(\mathrm{cm} \mathrm{cm}^{-3}\right)$.

O K extraível do solo (Mehlich-1) foi determinado nas subamostras retiradas das placas. Para subsidiar a interpretação dos resultados, também foram determinados o carbono orgânico total (COT analisador Shimadzu TOC- V CSH) e a estabilidade de agregados em água, segundo a metodologia descrita por Kemper \& Chepil (1965), com alterações propostas por Carpenedo \& Mielniczuk (1990) e Silva \& Mielniczuk (1997).

Nas plantas de milho, foram determinados a massa seca da parte aérea e o teor de $\mathrm{K}$ no tecido vegetal (Tedesco et al., 1995), com os quais se calculou o acúmulo desse nutriente na parte aérea. $\mathrm{Na}$ sequência, foi determinada a eficiência de utilização de $\mathrm{K}\left(\mathrm{EUK}=\mathrm{MSPA}^{2} \mathrm{CK}^{-1}\right)$, representada pela razão entre a produção de matéria seca na parte aérea do milho pelo acúmulo de K na mesma, conforme proposto por Siddiqi \& Glass (1981).

Para as avaliações de $\mathrm{K}$ e raízes nas camadas dos monólitos, foi utilizado o seguinte modelo:

$$
\mathrm{Y}_{\mathrm{ijk}}=\mu+\mathrm{A}_{\mathrm{i}}+\operatorname{rep}(\mathrm{A})_{\mathrm{ik}}+\mathrm{B}_{\mathrm{j}}+(\mathrm{AB})_{\mathrm{ij}}+\mathrm{E}_{\mathrm{ijk}}
$$

em que $\mu$ : média geral do experimento; A: sistemas de manejo $(\mathrm{i}=1,2,3,4,5,6)$; $\mathrm{B}$ : profundidades ( $\mathrm{j}=1,2,3,4,5,6)$; e E: erro experimental.

Para as avaliações na parte aérea e comprimento total de raízes, foi utilizado o modelo: 


$$
\mathrm{Y}=\mu+\mathrm{A}_{\mathrm{i}}+\operatorname{rep}(\mathrm{A})_{\mathrm{ik}}+\mathrm{Ei}_{\mathrm{jk}}
$$

em que $\mu$ : média geral do experimento; A: sistemas de manejo (i = 1,2,3,4,5,6); e E: erro experimental.

No caso de significância de análise de variância, foi utilizado o teste de Tukey $(p<0,05)$ para a distinção entre médias.

\section{RESULTADOS E DISCUSSÃO}

Os teores de $\mathrm{K}$ disponível se enquadram nas faixas "muito alto" e "alto" (CQFSRS/SC, 2004) até as profundidades de 10 e $20 \mathrm{~cm}$, respectivamente (Figura 3a), e os teores, em torno de $50 \mathrm{mg} \mathrm{dm}^{-3}$, até a profundidade de $40 \mathrm{~cm}$, enquadram-se na faixa "médio". Esses valores podem ser devidos ao teor inicial de K, ao seu acúmulo pela adubação potássica durante 18 anos consecutivos e também pela intemperização do material de origem do solo, que é rico em feldspatos de K (Meurer et al., 1996).

Para os teores de K no solo, foi observada interação $(p<0,05)$ entre os sistemas de manejo e a profundidade, havendo, entretanto, somente efeito de profundidade em cada sistema de manejo. Para a densidade de raízes, houve efeito $(p<0,05)$ de sistemas de manejo em cada profundidade. Os teores de $\mathrm{K}$ disponível (Figura 3a) e a densidade de raízes (Figura 3b e Quadro 2) se concentraram na camada superior e diminuíram em profundidade. A estratificação de $\mathrm{K}$ (Mallarino \& Borges, 2006) e de raízes (Silva et al., 2000) pode ocorrer independentemente do sistema de manejo e do modo de adubação. No entanto, a distribuição de $\mathrm{K}$ no perfil do solo, especialmente na camada de 0-5 cm, não teve relação com a distribuição de raízes. Embora as raízes da planta de milho se acumulem nessa camada (Waisel et al., 2002), o que tem sido verificado é que a distribuição de raízes no solo é mais influenciada pela distribuição de $\mathrm{P}$ do que de $\mathrm{K}$ (Schenk \& Barber, 1980; Mollier \& Pellerin, 1999). Uma estratificação de $\mathrm{K}$ similar à deste estudo, independente do manejo, também foi verificada por

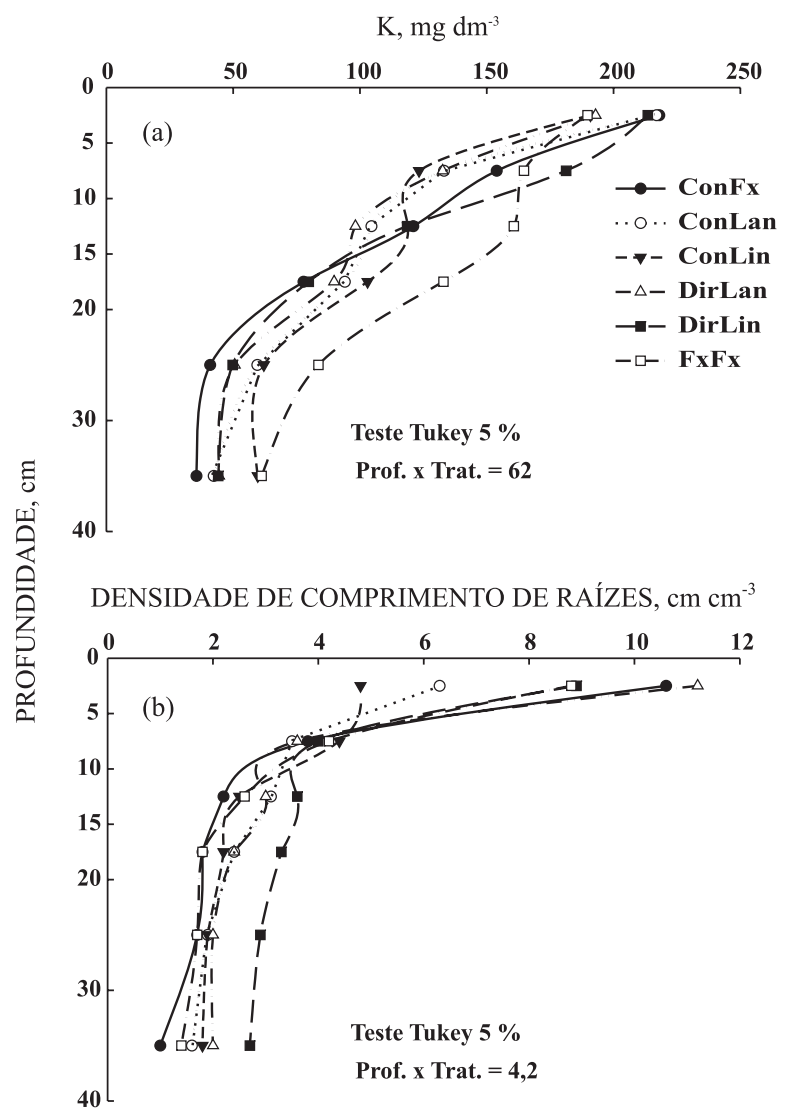

Figura 3. Distribuição de potássio (Mehlich-1) (a) e da densidade de raízes (b) no perfil de um Argissolo Vermelho conduzido por 18 anos em diferentes sistemas de manejo: convencional faixa (Con/Fx), convencional - lanço (Con/Lan), convencional - linha (Con/Lin), plantio diretolanço (Dir/Lan), plantio direto - linha (Dir/Lin) e faixa - faixa (Fx/Fx),- safra 2006/07.

Mallarino \& Borges (2006). Todavia, o acúmulo de K nas camadas superficiais do solo $(0-5 \mathrm{~cm})$, nos sistemas com revolvimento mais intenso (Con/Fx, Con/

Quadro 2. Densidade de raízes no perfil de um Argissolo Vermelho manejado com diferentes sistemas de cultivo por 18 anos

\begin{tabular}{ccccccc}
\hline \multirow{2}{*}{ Camada } & \multicolumn{5}{c}{ Sistema de manejo do solo ${ }^{(1)}$} \\
\cline { 2 - 6 } & Con/Lin & Con/Lan & Con/Fx & Dir/Lin & Dir/Lan & Fx/Fx \\
\hline cm & $27 \mathrm{a}$ & $34 \mathrm{a}$ & $50 \mathrm{a}$ & $35 \mathrm{a}$ & $47 \mathrm{a}$ & $43 \mathrm{a}$ \\
$0-5$ & $25 \mathrm{ab}$ & $18 \mathrm{~b}$ & $18 \mathrm{~b}$ & $15 \mathrm{~b}$ & $15 \mathrm{~b}$ & $20 \mathrm{~b}$ \\
$5-10$ & $15 \mathrm{bc}$ & $16 \mathrm{~b}$ & $11 \mathrm{bc}$ & $14 \mathrm{~b}$ & $12 \mathrm{~b}$ & $13 \mathrm{bc}$ \\
$10-15$ & $12 \mathrm{c}$ & $13 \mathrm{~b}$ & $8 \mathrm{bc}$ & $13 \mathrm{~b}$ & $10 \mathrm{~b}$ & $9 \mathrm{c}$ \\
$15-20$ & $11 \mathrm{c}$ & $10 \mathrm{~b}$ & $8 \mathrm{bc}$ & $12 \mathrm{~b}$ & $8 \mathrm{~b}$ & $8 \mathrm{c}$ \\
$20-30$ & $10 \mathrm{c}$ & $9 \mathrm{~b}$ & $5 \mathrm{c}$ & $11 \mathrm{~b}$ & $8 \mathrm{~b}$ & $7 \mathrm{c}$ \\
$30-40$ & & & & & \\
\hline
\end{tabular}

(1) Com: convencional; Dir: direto; Lin: linha; Lan: lanço; Fx: faixa. Médias seguidas da mesma letra na coluna não diferem pelo teste de Tukey $(p<0,05)$. 
Lan - Figura 3a), chama atenção, visto que este gradiente geralmente é observado no sistema plantio direto (Holanda et al., 1998). A distribuição mais profunda de $\mathrm{K}$ no perfil do solo foi verificada no preparo e adubação em faixa (Figura 3a). O cultivo mínimo tem resultado no aumento de $\mathrm{K}$ em profundidade (Opuku et al., 1997), com efeito notório para o desenvolvimento do milho (Yibrin et al., 1993; Heckman \& Kamprath, 1995).

No plantio direto, em longo prazo, há aumento na ciclagem de $\mathrm{K}$ devido à mineralização da matéria orgânica no solo, advindo do acúmulo de resíduos no solo (Mielniczuk, 2005), e à maior atividade microbiana. O sistema também acarreta maior agregação (Figura 1), resultando em continuidade de poros (Schaefer et al., 2001) e, consequentemente, no deslocamento do K com o fluxo da água que infiltra no solo (Silva, 1996). Neste trabalho, este comportamento não foi observado (Figura 3a), evidenciando o acúmulo de K, com o tempo, em superfície mesmo em sistemas nos quais o solo foi revolvido (Muzilli, 1983).

Nos sistemas com revolvimento do solo, a mobilização do solo contribui para a decomposição da matéria orgânica (Quadro 1) e degradação da estrutura do solo (Figura 1), o que poderia provocar a lixiviação de $\mathrm{K}$ para camadas abaixo daquelas avaliadas. Silva et al. (2006) observaram, após 17 anos, na mesma área experimental, comportamento semelhante, ressaltando os menores teores de carbono orgânico (CO) no solo sob SPD na camada de $0-7,5 \mathrm{~cm}$ e o possível efeito da intensidade de preparo e incorporação de resíduos ao solo na distribuição do $\mathrm{CO}$ no perfil do solo. Resultados semelhantes nesse mesmo manejo de solo também foram observados por Vyn \& Raimbault (1992). O cultivo mínimo tem resultado no aumento de K em profundidade (Yibrin et al., 1993; Opuku et al., 1997).

A estratificação de raízes (Figura 3b e Quadro 2) é mais acentuada do que a observada para o $\mathrm{K}$ (Figura 3a). Com exceção do Con/Lin e Con/Lan, houve um acúmulo de raízes na camada de $0-5 \mathrm{~cm}$. Tal comportamento pode resultar em restrições ao desenvolvimento das plantas em períodos de déficit hídrico (Davies \& Zhang, 1991). Deve-se enfatizar que em todos os sistemas de manejo, em torno de $70 \%$ das raízes de milho se concentraram na camada de 0-15 cm (Quadro 2), corroborando os dados obtidos por Silva et al. (2000). O acúmulo de raízes nas camadas superficiais $(0-5 \mathrm{~cm})$, principalmente no Dir, pode estar relacionado com melhor estado de agregação do solo nessa camada em relação ao Con, representado pela maior ocorrência de agregados maiores que 2,00 mm (Figura 1). A presença das raízes no solo, principalmente de gramíneas, favorece as ligações entre partículas do solo, contribuindo, desta forma, para a formação e estabilização de agregados (Carpenedo \& Mielniczuk, 1990; Silva \& Mielniczuk, 1997). A maior agregação reflete o maior acúmulo de raízes e, ao mesmo tempo, também é oriunda do acúmulo de $\mathrm{CO}$ nas camadas superficiais (Quadro 1), o que contribui para o crescimento radicular nesta região. As relações do $\mathrm{CO}$ com a agregação e a presença de raízes são interdependentes, e a afirmação de causa e efeito é relativa, visto que no sistema soloplanta-atmosfera as interações mútuas podem incapacitar a distinção dos papéis individuais dos agentes.

A falta de correlação entre a distribuição de $\mathrm{Ke}$ de raízes gerou a necessidade de se verificar a distribuição espacial desse nutriente e das raízes, em virtude dos diferentes graus de contato fertilizantesolo oriundos dos sistemas de manejo. De modo geral, independentemente do sistema de manejo, o K apresentou certa similaridade de distribuição no perfil do solo, tanto no sentido horizontal quanto no vertical (Figuras 4 e 5), e, em magnitude, estes valores divergem. Tais resultados corroboram aqueles observados por Klepker \& Anghinoni (1995) e Cavalcante et al. (2007).

No solo sem revolvimento (Dir), o K se concentrou até $15 \mathrm{~cm}$, com valores duas vezes maiores em relação ao sistema com revolvimento (Con). No entanto, o revolvimento do solo (Con) com incorporação do adubo aplicado a lanço, em linha ou em faixas por 18 anos, acarretou teores mais elevados de K, em torno de $50 \mathrm{mg} \mathrm{dm}^{-3}$, a partir dos $15 \mathrm{~cm}$ de profundidade. Essa distribuição é bem evidente na comparação Dir/Lin vs Con/Lin (Figura 5a,b). Tais gradientes são, no entanto, menores do que aqueles encontrados por Klepker \& Anghinoni (1995) no segundo ano do experimento, provavelmente pelo acúmulo, no tempo, desse nutriente no perfil do solo. Aumentos de K em profundidade pelo revolvimento do solo foram também observados por Morrison \& Chichester (1994). Esse aumento dos teores de $\mathrm{K}$ nas camadas mais profundas é importante na disponibilidade de $\mathrm{K}$ para as plantas, uma vez que é distribuído de forma mais homogênea no volume de solo explorado pelas raízes das culturas (Rehm \& Lamb, 2004). Assim, neste trabalho, mesmo após 18 anos, o manejo do solo e da adubação e a distribuição de $\mathrm{K}$ no perfil do solo não afetaram, de forma significativa, a distribuição das raízes no perfil do solo (Figuras 4 e 5), como verificado anteriormente por Klepker \& Anghinoni (1995) e Vyn \& Janovicek (2001). Isto indica que não é a presença desse nutriente que induz o crescimento radicular. No entanto, a associação entre os teores de $\mathrm{K}$ do solo e o crescimento de raízes foi observada em solos com baixa disponibilidade de K (Hallmark \& Barber, 1981; Peterson \& Barber, 1981; Rosolem et al., 2003). Neste sentido, devido aos teores na faixa "médio" de K no solo ao início do experimento, os valores de densidade radicular em torno de 25 e $10 \mathrm{~cm} \mathrm{~cm}^{-3}$ nos sistemas Dir/Lan e Con/Lan, na camada superficial $(0-5 \mathrm{~cm})$, respectivamente, e ao redor de $25 \mathrm{~cm} \mathrm{~cm}^{-3}$ nos tratamentos Dir/Lin e Con/Lin (Figuras 4d,e, e 5d,e,) podem ser atribuídas ao grau de revolvimento do solo e à aplicação do fertilizante fosfatado concomitantemente ao K (Costa, 2008). 
Plantio direto - lanço
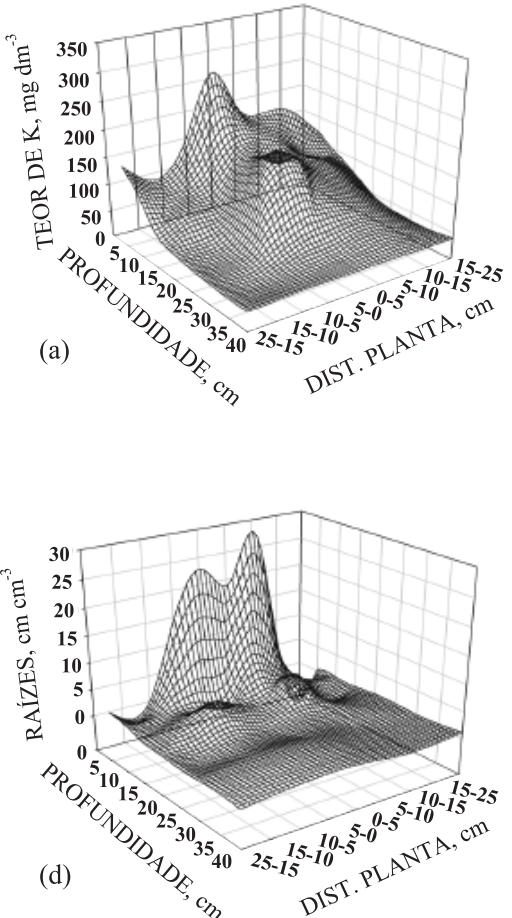

Convencional - lanço
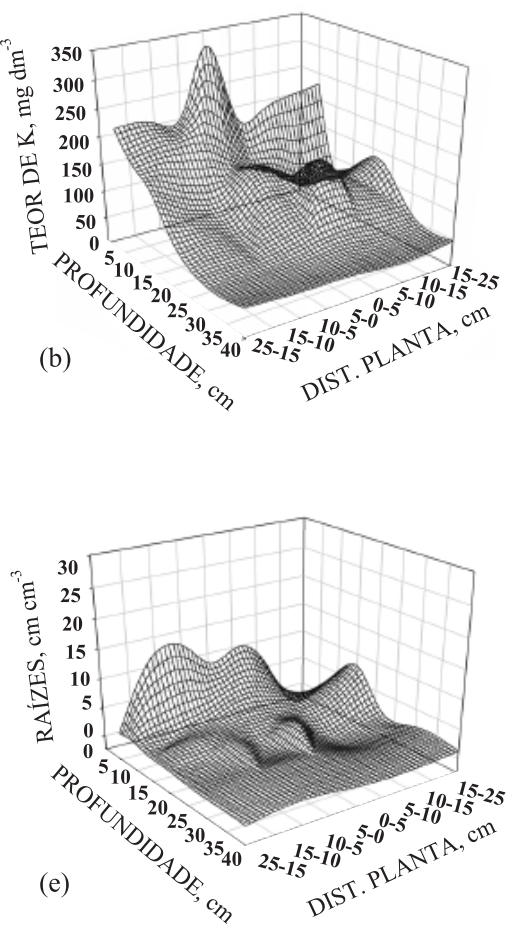

Convencional - faixa
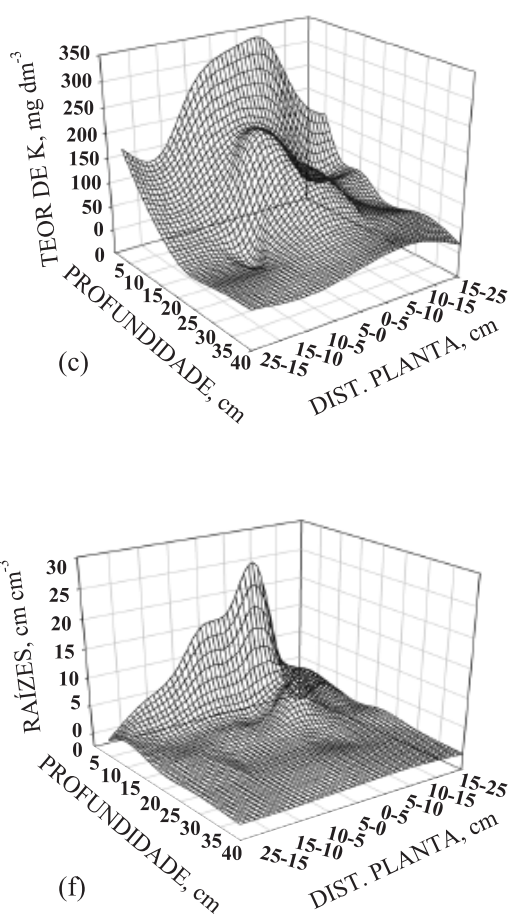

Figura 4. Distribuição de potássio (a, b e c) e de raízes (d, e e f) no início do enchimento de grãos de milho, no perfil de um Argissolo Vermelho sob os sistemas de manejo: plantio direto-lanço, convencional-lanço e preparo em convencional-faixa, respectivamente, por 18 anos.
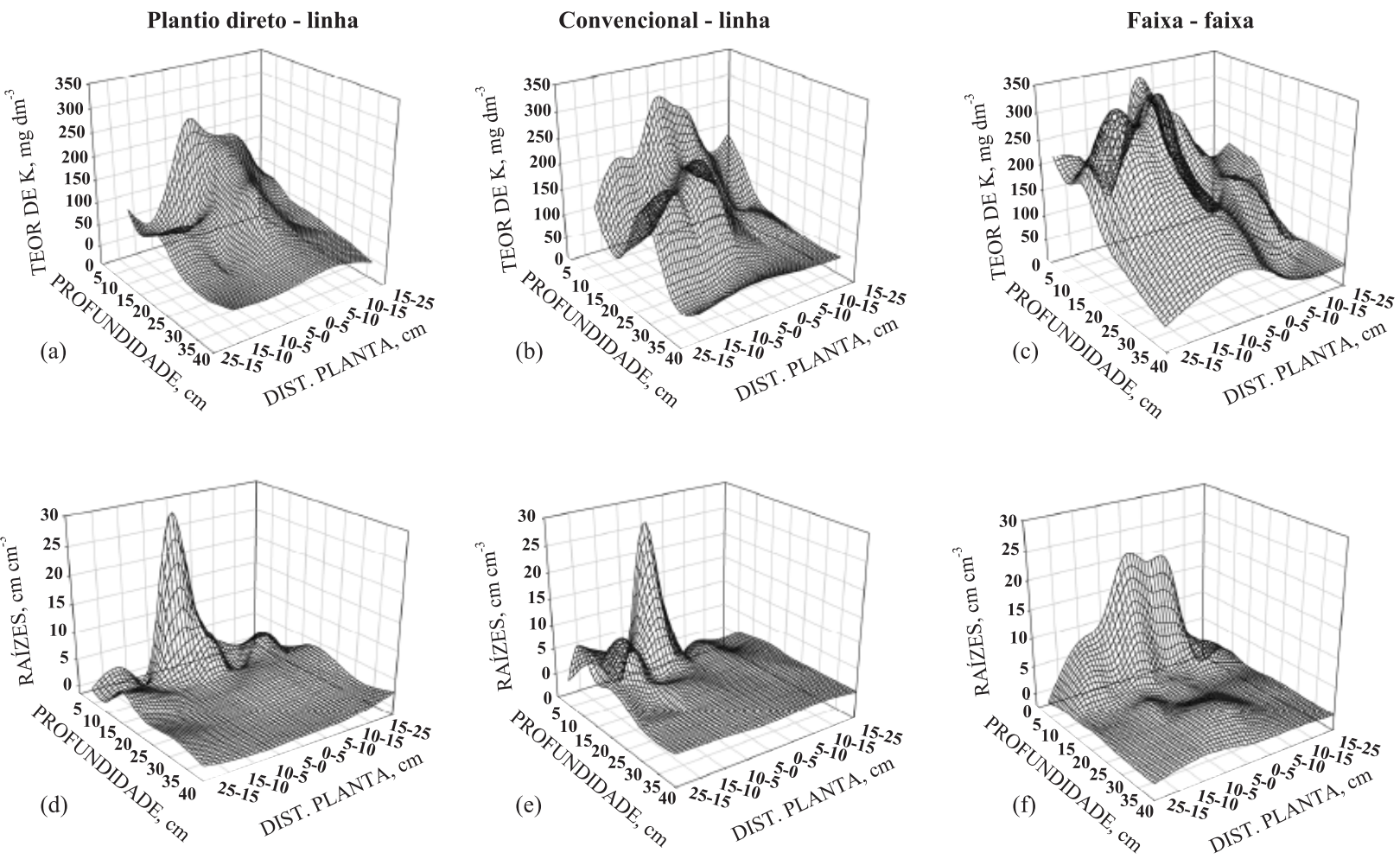

Figura 5. Distribuição de potássio (a, b e c) e de raízes (d, e e f) no início do enchimento de grãos de milho, no perfil de um Argissolo Vermelho sob os sistemas de manejo: plantio direto-linha, convencional-linha e preparo em faixa-faixa, respectivamente, por 18 anos. 
Apesar da ocorrência de variações na distribuição do K no perfil do solo, parece que, independentemente do sistema de manejo, há um acúmulo desse nutriente nas proximidades do colmo da planta de milho e diminuição dos teores à medida que há um afastamento da linha de semeadura e em profundidade (Figuras 4a,b,c e 5a,b,c). Tal comportamento pode ser atribuído ao fenômeno conhecido como "lavagem de K” (Klepker \& Anghinoni, 1995). A absorção intensa de $\mathrm{K}$ pela planta de milho resulta numa redução temporária de seu teor no solo (Sanzonowicz \& Mielniczuk, 1985), que, posteriormente, pela lavagem do $\mathrm{K}$ das folhas e colmos pela água, gera um gradiente radial a partir do colmo (Silva \& Ritchey, 1982). A ocorrência do fenômeno de lavagem do $\mathrm{K}$ se dá pelo fato desse nutriente não fazer parte da estrutura química de compostos orgânicos na planta (Marschner, 1995). O acúmulo de K na parte aérea das plantas de milho, em torno de 3,0 a 5,0 g/planta (Quadro 3), duas e meia vezes a quantidade aplicada ao solo, em torno de $1,7 \mathrm{~g} / \mathrm{planta}$, juntamente com a sua concentração no solo na base do colmo, independente do sistema de manejo, indica a ocorrência da lavagem de $\mathrm{K}$ a partir da parte aérea da planta.

A distribuição de $\mathrm{K}$ e de raízes de milho no perfil do solo não influenciou o crescimento e acúmulo de $\mathrm{K}$ pelo milho, pois os maiores comprimentos de raízes no Dir (Lan e Lin) (Quadro 3) não se refletiram na produção de MSPA ou no acúmulo de K pelas plantas de milho. $\mathrm{O}$ acúmulo de resíduos vegetais na superfície do solo, em razão da baixa mobilização do solo, em sistemas conservacionistas tem contribuído para maior proliferação de raízes nas camadas superficiais (Yibrin et al., 1993), que, muitas vezes, em sistemas com intenso revolvimento do solo, não é compensado pelo desenvolvimento de raízes nas camadas mais profundas. A disponibilidade inicial de $\mathrm{K}$ é determinante na sua absorção e acúmulo no tecido das plantas de milho (Vyn \& Jovanicek, 2001), tornando críticos os teores desse nutriente nas camadas superficiais. Neste sentido, as aplicações a lanço, independentemente do tipo de preparo do solo, resultaram em maior eficiência de uso de K (EUK) pela cultura do milho (Quadro 3). Ainda, o maior acúmulo de $\mathrm{K}$ que ocorreu nos sistema $\mathrm{Fx} / \mathrm{Fx}$ pode ser reflexo do efeito da mobilização parcial do solo no processo de acumulação de K pela planta de milho. Segundo Mallarino (1999), no sistema de manejo $\mathrm{Fx} /$ Fx, quando os teores de K estão abaixo do nível crítico, caso deste estudo, há em maior acúmulo de $\mathrm{K}$ pelo milho. Os teores elevados de K na linha de semeadura oriundos das aplicações localizadas (Lin) (Figuras 5a,b) aparentemente não provocaram restrição na sua absorção pelas plantas de milho (Quadro 3). O acúmulo de $\mathrm{K}$ nas proximidades do colmo da planta de milho na época de amostragem não serve como suporte para explicar o uso desse nutriente pela planta. A absorção de $\mathrm{K}$ pelo milho é máxima nas fases iniciais de desenvolvimento (Coelho, 2005) quando o fenômeno da lavagem desse nutriente ainda não havia ocorrido, de modo que os teores não se encontravam em níveis que comprometessem a absorção de K pelo milho.

Os resultados verificados ilustram bem a alteração que sistemas de manejo promovem na dinâmica do $\mathrm{K}$ no solo, refletindo de forma significativa nos padrões de adubação a serem considerados (Foloni \& Rosolem, 2008). Esses autores chamam atenção inclusive para a possibilidade de antecipação das adubações potássicas, visando suprir a elevada demanda inicial de $\mathrm{K}$ pelo milho. $\mathrm{O}$ acúmulo de $\mathrm{K}$ nas raízes deve ser contabilizado na avaliação da absorção de K pelo milho (Rosolem et al., 2003), embora, neste caso, parece que os teores iniciais de K no solo, na camada de $0-15 \mathrm{~cm}$, em torno de $135 \mathrm{mg} \mathrm{dm}^{-3}$, determinaram menor resposta do milho aos sistemas de manejo. Teores maiores que $1,5 \mathrm{cmol}_{\mathrm{c}} \mathrm{dm}^{-3}$ na camada de $10-20$, segundo revisão de Brunetto et al. (2005), resultam em baixas repostas às adubações potássicas em solos

Quadro 3. Produção de matéria seca da parte aérea de milho (MSPA), comprimento total de raízes (CTR) no perfil de um Argissolo Vermelho e acúmulo de potássio em plantas de milho (K parte aérea) e eficiência na utilização de K pelo milho (EUK) no monólito coletado no início do enchimento de grãos, em função de sistemas de manejo (valores de plantas individuais) - safra 2006/07

\begin{tabular}{|c|c|c|c|c|}
\hline Sistema de manejo ${ }^{(1)}$ & MSPA & CTR & K parte aérea & EUK \\
\hline & g/planta & $\mathrm{m} \mathrm{m}^{3}$ & g/planta & $\mathrm{g}^{2} \mathrm{mg}^{-1}$ \\
\hline Con/Lan ${ }^{(1)}$ & $227 \mathrm{a}$ & $2,88 \mathrm{bc}$ & $3,6 \mathrm{ab}$ & $14,4 \mathrm{a}$ \\
\hline Dir/Lan & $202 \mathrm{abc}$ & $3,53 \mathrm{a}$ & $3,1 \mathrm{~b}$ & $13,2 \mathrm{a}$ \\
\hline Con/Lin & $190 \mathrm{bc}$ & $2,20 \mathrm{~d}$ & $3,2 \mathrm{~b}$ & $11,3 \mathrm{bc}$ \\
\hline Dir/Lin & $178 \mathrm{c}$ & $3,39 \mathrm{a}$ & $3,0 \mathrm{~b}$ & $10,6 \mathrm{c}$ \\
\hline Con/ Fx & $183 \mathrm{c}$ & $2,65 \mathrm{bcd}$ & $3,1 \mathrm{~b}$ & $10,8 \mathrm{c}$ \\
\hline $\mathrm{Fx} / \mathrm{Fx}$ & $219 a b$ & $2,57 \mathrm{~cd}$ & $4,2 \mathrm{a}$ & $11,5 \mathrm{bc}$ \\
\hline
\end{tabular}

\footnotetext{
${ }^{(1)}$ Con: convencional; Dir: direto; Lin: linha; Lan: lanço; Fx: faixa. Médias seguidas da mesma letra na coluna não diferem entre si pelo teste de Tukey a $5 \%$.
} 
com minerais primários e secundários ricos em $\mathrm{K}$. Os valores de MSPA parecem ser reflexos deste comportamento. A elevada correlação entre a MSPA e o acúmulo de $K(0,54)$ pode ser devido à associação entre o acúmulo desse nutriente na parte aérea e a produção de biomassa. Comportamento semelhante também foi verificado por Vyn \& Janovicek (2001), embora esses autores tenham ressaltado que, no sistema convencional, independentemente do modo de adubação, os valores de MSPA no Dir e Fx foram em torno de 75 a $95 \%$ dos valores obtidos no sistema convencional. Segundo esses autores, períodos prolongados de estiagem afetam diretamente o acúmulo de $\mathrm{K}$ e a produção de biomassa da parte aérea do milho, de modo que as irrigações realizadas parecem ter anulado tal efeito.

\section{CONCLUSÕES}

1. Independente do manejo do solo e da adubação, o K tendeu a se distribuir no solo de forma similar ao longo do tempo, formando gradientes a partir da superfície e em torno do colmo do milho.

2. Os gradientes foram diferenciados em relação ao manejo do solo, concentrando-se mais na superfície em plantio direto e aumentando em profundidade no manejo convencional.

3. As raízes de milho se concentraram na camada superficial do solo, com maior crescimento em plantio direto, independentemente do modo de adubação.

4. A absorção de $\mathrm{K}$ e o crescimento do milho não foram associados à distribuição desse nutriente e de raízes em função dos manejos adotados.

5. A eficiência de utilização de K pelas plantas foi favorecida pela aplicação a lanço do adubo potássico, independente do preparo do solo.

\section{AGRADECIMENTOS}

A equipe da Estação Experimental Agronômica da UFRGS, ao laboratorista Adão Luís Ramos dos Santos pelo apoio no campo e laboratório e ao pesquisador da Embrapa Dirceu Klepker pelo auxílio nos dados.

\section{LITERATURA CITADA}

BALL-COELHO, B.R.; ROY, R.C. \& SWANTON, C.J. Tillage alters corn root distribution in coarse-textured soil. Soil Till. Res., 45:237-249, 1998

BARBER, S.A. Soil nutrient bioavailability. New York, John Wiley \& Sons, 1995. 414p.

BAYER, C. \& MIELNICZUK, J. Características químicas do solo afetadas por métodos de preparo e sistemas de cultura. R. Bras. Ci. Solo, 21:105-112, 1997.
BEVILAQUA, G.A.P.; BROCH, D.L.; POSSENTI, J.C. \& VILLELA, F.A. Posição do fósforo e potássio na adubação da semente e no crescimento de plântulas de milho. R. Bras. Agroci., 2:87-92, 1996.

BORDOLI, J.M. \& MALLARINO, A.P. Deep and shallow banding of phosphorus and potassium as alternatives to broadcast fertilization for no-till corn. Agron. J., 90:2733, 1998.

BRUNETTO, G.; GATIBONI, L.C.; SANTOS, D.R.; SAGGIN, A. \& KAMINSKI, J. Nível crítico e resposta das culturas ao potássio em um Argissolo sob sistema plantio direto. R. Bras. Ci. Solo, 29:561-571, 2005.

CARPENEDO, V. \& MIELNICZUK, J. Estado de agregação e qualidade de agregados de Latossolos roxos, submetidos a diferentes sistemas de manejo. R. Bras. Ci. Solo, 14:99105,1990

CAVALCANTE, E.G.S.; ALVES, M.C.; PEREIRA, G.T. \& SOUZA, Z.M. Variabilidade espacial de MO, P, K, e CTC do solo sob diferentes usos e manejos. Ci. Rural, 37:394400, 2007.

COELHO, A.M. O potássio na cultura do milho. In: YAMADA, T. \& ROBERTS, T.L. Potássio na agricultura brasileira. Piracicaba, Potafos, 2005. p.613-658

COMISSÃO DE QUÍMICA E FERTILIDADE DO SOLO CQFSRS/SC. Manual de adubação e calagem para os Estados do Rio Grande do Sul e de Santa Catarina. 10.ed. Porto Alegre, 2004. 400p.

COSTA, S.E.V.G.A. Distribuição de fósforo, de potássio e de raízes e rendimento de milho em sistemas de manejo do solo e da adubação em longo prazo. Porto Alegre, Universidade Federal do Rio Grande do Sul, 2008. 116p. (Tese de Mestrado)

DAVIES, W.J. \& ZHANG, J. Root signals and the regulation of growth and development of plants in drying soil. Ann. Rev. Plant Physiol. Plant Molec. Biol., 42:55-76, 1991.

ELTZ, F.L.F.; PEIXOTO, R.T.G. \& JASPER, F. Efeitos de sistemas de preparo do solo nas propriedades físicas e químicas de um Latossolo Bruno álico. R. Bras. Ci. Solo, 13:259-267, 1989.

EMPRESA BRASILEIRA DE PESQUISA AGROPECUÁRIA EMBRAPA. Centro Nacional de Pesquisa de Solos. Sistema brasileiro de classificação de solos. 2.ed. Rio de Janeiro, 2006. 306p.

FOLONI, J.S.S. \& ROSOLEM, C.A. Produtividade e acúmulo de potássio na soja em função da antecipação da adubação potássica no sistema plantio direto. R. Bras. Ci. Solo, 32:1549-1561, 2008.

GUIMARÃES, M.F.; JORGE, L.A.C.; DE MARIA, I.C.; TAVARES FILHO, J.; BICUDO, S.J. \& CRESTANA, S. Três metodologias de avaliação de raízes: Descrição, limitações e vantagens. In: SIMPÓSIO NACIONAL DE INSTRUMENTAÇÃOO AGROPECUÁRIA - SIAGRO, 1., São Carlos, 1996. Anais. São Carlos, Embrapa/CNPDIA, 1997. p.295-304.

HALLMARK, W.B. \& BARBER, S.A. Root growth and morphology, nutrient uptake, and nutrient status of soybeans as affected by soil $\mathrm{K}$ and bulk density. Agron. J., 73:779-782, 1981. 
HECKMAN, J.R. \& KAMPRATH, E.J. Potassium accumulation and corn yield related to potassium fertilizer rate and placement. Soil Sci. Soc. Am. J., 56:141-148, 1992.

HECKMAN, J.R. \& KAMPRATH, E.J. Potassium accumulation and soybean yield related to potassium fertilizer rate and placement. Comm. Soil Sci. Plant Anal., 26:123-143, 1995.

HOLANDA, F.S.R.; MENGEL, D.B.; PAULA, M.B.; CARVALHO, J.G. \& BERTONI, J.C. Influence of crop rotation in tillage systems on phosphorus and potassium stratification and root distribution in the soil profile. Comm. Soil Sci. Plant Anal., 29:2382-2394, 1998.

ISHAQ, M.; IBRAHIM, M. \& LAL, R. Tillage and fertilizer effects on root growth of wheat and cotton on a sandy clay loam in Pakistan. J. Sust. Agric., 22:43-57, 2003.

KARLEN, D.L.; FLANNERY, R.L. \& SADLER, E.J. Aerial accumulation and partitioning of nutrients by corn. Agron. J., 80:232-242, 1988.

KAYSER, M. \& ISSELSTEIN, J. Potassium cycling and losses in grassland systems: A review. Grass. For. Sci., 60:213224,2005

KEMPER, W.D. \& CHEPIL, W.S. Size distribution of aggregation. In.: BLACK, C.A., ed. Methods of soil analysis. Madison, American Society of Agronomy, 1965. p.499510 .

KETCHESON, W.J. Effect of tillage on fertilizer requirements for corn on a silt loam soil. Agron. J., 72:540-542, 1980.

KLEPKER, D. \& ANGHINONI, I. Características físicas e químicas do solo afetadas por métodos de preparo e modos de adubação. R. Bras. Ci. Solo, 19:395-401, 1995.

LUPWAYI, N.Z.; CLAYTON, G.W.; HARKER, K.N.; TURKINGTON, T.K. \& JOHNSTON, A.M. Impact of crop residue type on potassium release. Better Crops, $89: 14-15,2005$

MALLARINO, A.P. Effects of four tillage systems and placement of phosphorus and potassium mixtures on grain yield in corn-soybean rotations and continuous corn 1999. Disponível em: <http://www.ag.iastate.edu/farms/ 05reports/ne/EffectFourTillage.pdf $>$ Acesso em: $10 \mathrm{de} \mathrm{dez.}$ de 2008.

MALLARINO, A.P. \& BORGES, R. Phosphorus and potassium distribution in soil following long-term deep-band fertilization in different tillage systems. Soil Sci. Soc. Am. J., 70:702-707, 2006

MARCOLAN, A.L. Atributos químicos de um Argissolo e rendimento de culturas em função do seu revolvimento na reaplicação de calcário no sistema plantio direto. Porto Alegre, Universidade Federal do Rio Grande do Sul, 2002. 70p. (Tese de Mestrado)

MARSCHNER, H. Mineral nutrition of higher plants. London, Academic Press, 1995. 889p.

MELLO IVO, W.M.P. \& MIELNICZUK, J. Influência da estrutura do solo na distribuição e na morfologia do sistema radicular do milho sob três métodos de preparo. R. Bras. Ci. Solo, 23:135-143, 1999.
MEURER, E.J.; KAMPF, N. \& ANGHINONI, I. Fontes potenciais de potássio em alguns solos do Rio Grande do Sul. R. Bras. Ci. Solo, 20:41-47, 1996.

MIELNICZUK, J. Manejo conservacionista da adubação potássica. In: YAMADA, T. \& ROBERTS, T.L. Potássio na agricultura brasileira. Piracicaba, Associação Brasileira para Pesquisa da Potassa e do Fosfato, 2005. p.165-178.

MODEL, N.S. \& ANGHINONI, I. Respostas do milho a modos e técnicas de preparo do solo. R. Bras. Ci. Solo, 16:55-59, 1992.

MOLLIER, A. \& PELLERIN, S. Maize root system growth and development as influenced by phophorus deficiency. J. Exper. Bot., 50:487-497, 1999.

MORRISON, J.E. \& CHICHESTER, F.W. Tillage system effects on soil and plant nutrient distributions on Vertisols. J. Prod. Agric., 7:364-373, 1994.

MOTTA, A.C.V.; NICK, J.A.; YORINORI, G.T. \& SERRAT, B.M. Distribuição horizontal e vertical da fertilidade do solo e das raízes de cafeeiro (Coffea arábica L.) cultivar Catuaí. Acta Sci. Agron., 28:455-463, 2006.

MUZILLI, O. Influência do sistema de plantio direto, comparado ao convencional, sobre a fertilidade da camada arável do solo. R. Bras. Ci. Solo, 7:95-102, 1983.

OPOKU, G.; VYN, T.J. \& SWANTON, C.J. Modified no-till systems for corn following wheat on clay soils. Agron. J., 89:549-556, 1997.

PEDÓ, F. Rendimento e distribuição de raízes de seis espécies de plantas em dois níveis de compactação do solo. Porto Alegre, Universidade Federal do Rio Grande do Sul, 1985. 92p. (Tese de Mestrado)

PETERSEN, M. Tillage and root development in corn- Is there a connection? Disponível em: <http:// www.precisiontillage.com/assets/uploads/ tillage_root\%20development\%20article.pdf $>$ Acesso em: 15 de maio de 2008.

PETERSON, W.R. \& BARBER, S.A. Soil and root morphology and K uptake. Agron. J., 73:316-319, 1981.

REHM, G.W. Impact of banded potassium for corn and soybean production in a ridge-till planting system. Comm. Soil Sci., 26:2725-2738, 1995.

REHM, G.W. \& LAMB, J.A. Impact of banded potassium on crop yield and soil potassium in ridge-till planting. Soil Sci. Soc. Am. J., 68:629-636, 2004.

ROSOLEM, C.A.; MATEUS, G.P.; GODOY, L.J.G.; FELTRAN, J.C. \& BRANCALIÃO, S.R. Morfologia radicular e suprimento de potássio às raízes de milheto de acordo com a disponibilidade de água e potássio. R. Bras. Ci. Solo, 27:875-884, 2003.

ROSSATO, R.R. Potencial de ciclagem de nitrogênio e potássio pelo nabo forrageiro intercalar ao cultivo do milho e trigo em plantio direto. Santa Maria, Universidade Federal de Santa Maria, 2004. 106p. (Tese de Mestrado)

SALTON, J.C.; FABRICIO, A.C.; TIRIONI, C. \& GANCEDO, M. Cloreto de potássio na linha de semeadura pode causar danos a soja. Dourados, Embrapa, 2002. (Comunicado Técnico, 64) 
SANZONOWICZ, C. \& MIELNICZUK, J. Fontes, doses e métodos de aplicação de potássio no solo. Pesq. Agropec. Bras., 20:189-195, 1985.

SCHAEFER, C.E.G.R.; SOUZA, C.M.; VALEJOS, M.F.J.; VIANA, J.H.M. \& GALVÀO, J.C.C. Características da porosidade de um argiloso vermelho amarelo submetido a diferentes sistemas de preparo de solo. R. Bras. Ci. Solo, $25,112-123,2001$.

SCHENK, M.K. \& BABER, S.A. Potassium and phosphorus uptake by corn genotypes grown in the field as influenced by roots characteristics. Plant Soil, 54:65-76, 1980.

SCHUURMAN, J.J. \& GOEDEWAAGEN, M.A.J. Methods for the examination of root systems and roots. Wageningen, Pudoc, 1965. 86p.

SIDDIQI, M.Y. \& GLASS, A.D. Utilization index: A modified approach to the estimation and comparison of nutrient efficiency in plants. J. Plant Nutr., 4:289-302, 1981.

SILVA, I.F. \& MIELNICZUK, J. Avaliação do estado de agregação do solo afetado pelo uso agrícola. R. Bras. Ci. Solo, 21:313-319, 1997.

SILVA, J.E. \& RITCHEY, K.D. Acumulação diferencial de potássio em oxissolos devido a lavagem do nutriente das plantas de milho para o solo. R. Bras. Ci. Solo, 6:183-188, 1982.

SILVA, L.S. Características químicas de um Latossolo nos sistemas plantio direto e convencional no primeiro ano. Porto Alegre, Universidade Federal do Rio Grande do Sul, 1996. 87p. (Tese de Mestrado)
SILVA, M.A.S.S.; MAFRA, A.L.; JACKSON, A.A.; ROSA, J.D.; BAYER, C. \& MIELNICZUK, J. Propriedades físicas e teor de carbono orgânico de um Argissolo vermelho sob distintos sistemas de uso e manejo. R. Bras. Ci. Solo, 30:329-337, 2006.

SILVA, V.R.; REINERT, D.J. \& REICHERT, J.M. Densidade do solo, atributos químicos e sistema radicular do milho afetados pelo pastejo e manejo do solo. R. Bras. Ci. Solo, 24:191-1999, 2000.

TEDESCO, M.J.; GIANELLO, C.; BISSANI, C.A.; BOHNEN, H. \& WOLKWEISS, S.J. Análises de solo, plantas e outros materiais. 2.ed. Porto Alegre, Universidade Federal do Rio Grande do Sul, 1995. 174p.

THORNTHWAITE, C.W. \& MATHER, R.J. The water balance. New Gersey, Laboratory of Climatology, 1955. v.8. 104p. (Publication in Climatology)

VYN, T.J. \& JANOVICEK, K.J. Potassium placement and tillage system effects on corn response following longterm no till. Agron. J., 93:487-495, 2001.

VYN, T.J. \& RAIMBAULT, B.A. Evaluation of strip tillages systems for corn production in Ontario. Soil Till. Res., 23:163-176, 1992.

WAISEL, Y.; ESHEL, A. \& KAFKAFI, U., eds. Plant roots the hidden half. 3.ed. New York, Marcel Dekker, 2002. 1136 p.

YIBRIN, H.; JOHNSON, J.W. \& ECKERT, D.J. No-till corn production as affected by mulch, potassium placement, and soil exchangeable potassium. Agron. J., 85:639-644, 1993. 